\title{
Factors Influencing The Choice Of Ophthalmology As A Career Amongst Students Of Dow University Of Health Sciences, Karachi
}

\author{
Hamidullah Ariff, Khowaja Faiz-ur-Rab, Shehlaa Dareshani, Tarique Saleem, Masood Hussain Rao
}

\section{ABSTRACT:}

Objective: To determine the factors influencing the choice of Ophthalmology as a career amongst Dow University of Health Sciences, Karachi.

Study design and Setting: A descriptive cross sectional study was conducted on fourth and final year students of Dow Medical College, DUHS, Karachi through non-probability consecutive sampling technique.

Methodology: Before conducting the study, permission from the Principal of Dow Medical College, Dow University of Health Sciences was taken. Overall 244 students were selected willing to participate in the study after having their written consent. A structured questionnaire with minor modification and after pretest was provided to them. All the information was filled by the student on their own reliability. The collected data was analyzed through SPSS version 21.0 . The quantitative data was assessed through mean and standard deviation whereas frequencies and percentages were developed for qualitative data. Chi square test was appl/ded to g/etermine any significant correlation between different variables.

Result: According to analysis of the data, $77 \%$ female and $23 \%$ male medical students of fourth and final year participated in the study. Overall $8.65 \%$ students were given their first choice of Ophthalmology which is at $4^{\text {th }}$ rank in all specialties after internal medicine, cardiology and paediatrics. The major factors which influence them to select Ophthalmology as their first choice were high income, less working hours and experience of medical and surgical field. The major factors, which restrict them not to choose Ophthalmology as a career, wereless opportunity of residency, long duration of residency and less opportunity at private sector.

Conclusion: Ophthalmology is at $4^{\text {th }}$ rank in the choice of participated medical students. The factors attracted them to choose it were high income, less working hours and no night shift. However less opportunity of residency and less working opportunity at private sector restricted them not to choose the ophthalmology as their career.

Keywords: career choice, future career, Medical education, medical students, Ophthalmology and specialty choice.

\section{INTRODUCTION:}

The choice of any medical specialty taken as future career is the key worldwide which has to be decided normally by medical students at their graduation level. This is also decided on the basis of availability of seats for each category ${ }^{1}$. World Health Organization recommended Physician to population ratio as $23: 10,000 .^{2}$ Many factors influence the medical

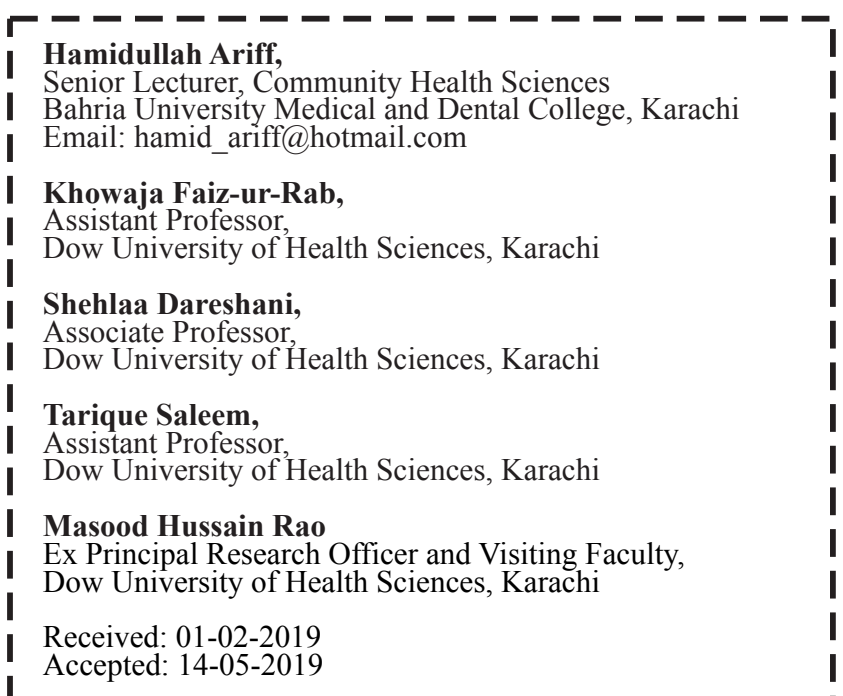

students to select their particular speciality ${ }^{3}$. Generally there are two main groups, one which is related to the personal interest, gender and their priority and second one is related to the environment in which they are working along with load of patients in their circumstances, their life style, less on calls and night working days. ${ }^{4,5,6}$ Even in United Kingdom, medical students while considering a choice of their career, the main important factors are short working days and job perception by the other people. ${ }^{7}$

In a study ${ }^{8}$ conducted in Nepal, the main influencing factors in medical students for selecting a speciality as their career were gender, marital status, availability of jobs abroad, job security and future scope. Gynaecology and ophthalmology were the best choices of female Nepali medical students as compared to males whose choices were Orthopaedics, General Surgery and Internal Medicine. The other influencing factors were workload flexibility and illness of a family member or a friend. In another study ${ }^{9}$ conducted in Jordan, competency of the individual and reputation of speciality were the main influencing factors to determine their choice of future planning. In this study, male's first choice was General Surgery whereas female's first choice was Gynaecology. Studies conducted in Saudi Arabia ${ }^{10,11,12}$ on students and new graduates determined that General Surgery, 
Paediatrics and ophthalmology were their best choices whereas main factors influencing for that were personal interest, flexibility of working hours, cultural values, speciality characters, prestige of the speciality and anticipated income. Similarly ophthalmology was the best choice due to shortage of Ophthalmologist in the country. In another study conducted in Nigeria ${ }^{13,14}$ the influencing factors in selecting ophthalmology as speciality were personal interest, life style and opportunity of surgery along with medicine. In a study conducted in Kenya ${ }^{15}$, work environment and pressure of family and friends were the main factors in selecting the career choice.

A very scattered regional literature focusing on the career choice of medical students is available. In a study conducted in Kolkata, India ${ }^{16}$, the main influencing factors were selfinterest and passion. In another study ${ }^{17}$ conducted in Iran, personal development, interest, motto of helping people, income and prestige, easiness and comfortable job were the most influencing factors in selecting the future career. Studies from Pakistan ${ }^{18,19,20}$ were also showing different results. The main influencing factors were suited to personality, time commitment, prestige/respect and international opportunity having ophthalmology as only preference by $2.3 \%$ participants. However these studies were done from first to final year students. This study was designed to determine the factors influencing the choice of ophthalmology as a career among medical students of Dow Medical College, Karachi.

\section{METHODOLOGY:}

A cross sectional analytical study was conducted on students of Dow Medical College, Karachi through non-probability consecutive sampling technique. Overall 244 students of fourth and final year MBBS were selected for the study who gave the consent to participate. A self-administered semistructured questionnaire comprising demographic data, questions regarding their future choice of specialities preferences and factors influencing them or restrict them to choose ophthalmology as a preference was distributed to them. All the information was filled by the student on their own reliability. The collected data was analyzed through SPSS version 21.0. The quantitative data was assessed through mean and standard deviation whereas frequencies and percentages were developed for qualitative data. Odd ratio at $95 \%$ confidence interval along with significance value at $\mathrm{P}<0.05$ was calculated to determine the difference factor influencing them to choose ophthalmology or any other field.

\section{RESULT:}

Over all 244 students were equally selected from fourth and final year MBBS classes through non-probability consecutive sampling method. Mean age of the student was $22.72 \pm 0.48$ years. Majority of the participants were females $\mathrm{n}=188$ $(77.0 \%)$ while males were $n=56(23 \%) .89 .3 \%$ were satisfied with their choice of medical field, and only $44.7 \%$ select this field as they wants to go abroad. Only $8.6 \%$ students have chosen ophthalmology as their first choice of career.

To determine the factors which either influences them to choose or not to choose ophthalmology as a career, different questions were asked. In response to first question whether part time work opportunities in ophthalmology are available or lacking, majority (62.3\%) said no part time opportunities are there as compared to other fields. In reply to a question regarding whether you have seen any Ophthalmologist as a role model satisfying family life, replies of majority $(70.9 \%)$ was no. $35.7 \%$ think that it is difficult to get a residency in ophthalmology. Majority of the respondents think that ophthalmology speciality has high income, personal experience in that field (56.1\%), and portrayal of different specialties in the media (51.6\%). However 57.8\% respondent students were of the view that the length of residency is more and $73.0 \%$ said that opportunity in private sector for ophthalmology is less. (Table 1)

In comparing the choice of all fields of specialist, Ophthalmology came at no.4 after internal medicine, cardiology and pediatrics for the medical students as first choice of their career in future where they can experience for medicine and surgical procedures both. (Fig 1)

Table1. Factor influencing the choice of ophthalmology as a career

\begin{tabular}{|l|c|c|}
\hline \multicolumn{1}{|c|}{ Factors } & Yes & No \\
\hline Opportunities for part time work in Ophthalmology & 92 & 152 \\
\hline How ophthalmologist role model have a satisfying family life & 71 & 173 \\
\hline The difficulty of getting into Ophthalmology Residency & 87 & 157 \\
\hline The high income & 205 & 39 \\
\hline Personal experience in that field (family member had a condition related to the specialty) & 137 & 107 \\
\hline Private sector opportunities & 66 & 178 \\
\hline Portrayal of different specialties in the media & 126 & 118 \\
\hline The length of residency years & 141 & 103 \\
\hline
\end{tabular}


Fig 1. Choice of Speciality

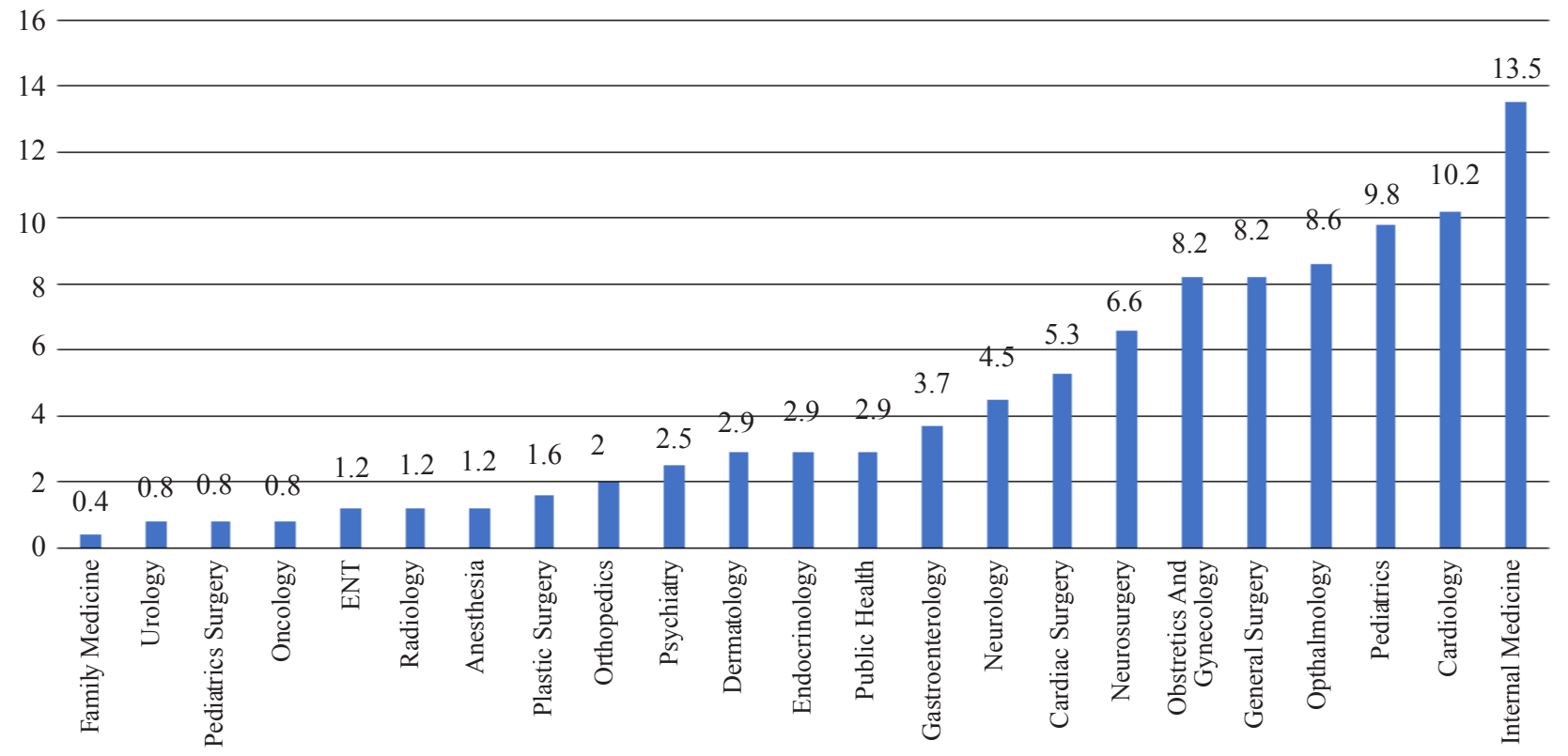

\section{DISCUSSION:}

Medical students are a country's future physician reservoirs. Knowing how they choose their specialties is the key in enforcing a balance in distributing physicians in different medical specialties ${ }^{4}$. Students of medical colleges have to select their medical specialty during their study with concern to their like and dislike, job opportunities for professional, income dignity of the profession. Amongst them, Ophthalmology is a major one which has grown exponentially more competitive, especially with the low capacity of training centres. ${ }^{21,22}$

According to a study ${ }^{1}$ conducted in Saudi Arabia, majority of participated students were males (65.5\%) and females on 34.55 with mean age of participants was $23.5 \pm 1.7$. In another study ${ }^{13} 45.6 \%$ were males and $54.4 \%$ were females with mean age $23.7 \pm 1.54$ years. In our study majority $(77 \%)$ were females and only $23 \%$ were males with mean age $22.72 \pm 0.48$. The reason for more females is admission ratio where it is around $80 / 20$ for females and males.

In the same study ${ }^{1}$, ophthalmology was the first choice for $10.2 \%$ students, while $44.7 \%$ wanted other medical specialities and $40.3 \%$ preferred surgical specialities. In another study ${ }^{23}$ ophthalmology was on second preferred choice of medical student after dermatology i.e. (14.4\%). In study of United Kingdom ${ }^{7}$ ophthalmology was found the first choice of long term career for $2.3 \%$ of male and $1.5 \%$ of females one year after qualification. It was just $0.9 \%$ in 1974 which has now become $2.3 \%$. In a study of Nigerian students $^{13}, 32.5 \%$ opted for ophthalmology after their one year youth service. In our study ophthalmology was the first choice of $8.6 \%$ students whereas $56.5 \%$ wanted other medical specialty and 34.9 preferred surgical speciality. The difference is due to male female ration in our set up as compared to others. In different studies it was also found that females were less interested in ophthalmology.

Multiple factors influenced medical students' choice when choosing a future speciality. Knowing these factors can help in directing work-force to choose specialities that are currently limited. There are different factors which either influences the student to choose or not to choose ophthalmology as their specialty in future. According to a study ${ }^{1}$, the factors which influence the student for choosing ophthalmology was high-income earning with as much as $54 \%$ of the participants giving it credit followed by private sector opportunities (40\%), part-time opportunities $(40 \%)$ and leisure (34\%). In a study conducted in $\operatorname{Iran}^{23}$ economic factors were deemed the most important factors in choosing ophthalmology as their specialties. In a study ${ }^{23}$ the factors influencing them to choose ophthalmology as a specialty was their commitment with their work strengthened by the prospect of attractive hours and working conditions. In Nigerian study ${ }^{13}$ the factors that influenced their choice of specialty as ophthalmology was mainly interest in the specialty $(85 \%)$, opportunity to combine medicine and surgery (33.8\%) as well as life style (42.5\%). In our study, Majority of the respondents who choose ophthalmology as their specialty think that ophthalmology specialty has high income (84\%), personal experience in that field (56.1\%), and portrayal of different specialties in the media (51.6\%).

There are some negative factors like difficulty of getting into the ophthalmology. According to a study ${ }^{1}$ ophthalmology 
Residency Program (53\%) was the most important factor that pushed students away from choosing ophthalmology. In our study, $57.8 \%$ respondent students were of the view that the length of residency in more and $73.0 \%$ said that opportunity in private sector for ophthalmology is less and there is major difficulty of getting into ophthalmology Residency.

\section{CONCLUSION:}

Ophthalmology is at $4^{\text {th }}$ rank in the choice of participated medical students. The factors attracted them to choose it were high income, less working hours and no night shift. However less opportunity of residency and less working opportunity at private sector restricted them not to choose the ophthalmology as their career.

\section{REFERENCES:}

1. Al Salman SA, Al Qahtani GM, Al Asmari BM, Alhumaid SRA, Masuadi E.Factorsin fluencing the choice of ophthalmology as a career among medical students of King Saud bin Abdul Aziz University Riyadh, Saudi Arabia. J Health Spec 2017; 5:212-8.

2. Kinfu Y, Dal Poz MR, Mercer H, Evans DB.The health worker shortage in Africa. Are enough physicians and nurses being trained? Bull WHO 2009;87:225-30

3. Alawad AAMA, Khan WS Abdelrazig YM, Elzain YI, khalil $\mathrm{HO}$, Ahmed OBE, et al, Factors considered by undergraduate medical students when selecting specialty of their future careers. Pan Afr Med J 2015; 20(2):102-7.

4. Dorsey ER, Jarjoura D, Rutecki GW. Influence of controllable life style on recent trends in spatiality choice by US medical students. JAMA2003;290:1173-8.

5. Wright B, Scott I, Woloschuk W, Brenneis F, Bradley J. Career choice of new medical students at three Canadian universities: Family medicine versus specialty medicine. CMAJ 2004; 170:1920-4.

6. Dorsey ER, Jarjoura D, Rutecki GW. The influence of controllable lifestyle and sex on the specialty choices of graduating U.S. Medical students, 1996-2003. Acad Med 2005;80:791-6.

7. Lambert TW, Goldacre MJ, Bron AJ. Career choices for ophthalmology made by newly qualified doctors in the United Kingdom, 1974-2005. BMC Ophthalmol 2008; 8(1):3.

8. Shrestha B, Pokhrel YR, Butterworth K, Determinants of postgraduate students' choices of speciality. J Nepal Med Assoc, 2016;54:1-7

9. Khader YS, Al-Zoubi D, Amarin Z, Al-Omari M. Factors affecting medical students in formulating their specialty preference in Jordan. 2008;8(1):32.
10. Al-Subaie N, Aldhofaian HS, Alhuwaimel L, Abu-Zaid A. Specialitypreferences and the factors influencing them among pre-clerkship medical students: The first study from Alfaisal University-College of Medicine, Saudi Arabia. Cureus 2016; 8(11): e894 DOI: 10.7759/cureus.894.

11. Zolaly MA, Kasim K, Mahmoud MI. Medical career selection among newly graduated physicians in Madinah, KSA. Med Teach 2013;35 Suppl1:S63-7.

12. Al Motowa S, Khandekar R, Al-Towerki A. Resources for eye care at secondary and tertiary level government institutions in Saudi Arabia. Middle East Afr J Ophthalmol 2014; 21:1426.

13. Oluwole OC. Factors influencing choice of specialty amongst Nigerian Ophthalmologists. Pak J Ophthalmol 2012; 28(1):1013.

14. Onyemaechi N, Bisi-Onyemaechi A, Omoke N I, Odetunde O I, Okwesili I C, OkwaraBO. Specialty choices: Patterns and determinants among medical undergraduates in Enugu Southeast Nigeria. Niger J ClinPract2017;20(11):1474-80.

15. Dossajee H, Obonyo N, Ahmed SM, Career preferences of final year medical students at a medical school in Kenya-A cross sectional study. BMC Med Educ 2016;16(1): 5-14.

16. Sarkar TK, Adhikary M, Chellaiyan DVG, Jana PK, Rai A, Biswas I. An observational study on career aspiration among students of a medical college in Kolkata. Int J Med Sci Public Health 2017;6(4):1-4.

17. Shakurnia H, Mozaffari A, Ghadiri A. Factors influencing choice of spatiality by medical residents in Ahvaz,Iran. Bangladesh Journal of Medical Science,2016;15(1):111-7.

18. Aslam M, Ali A, Taj T, Badar N, Mirza W, Ammar A, et al.Specialty choices of medical students and house officers in Karachi, Pakistan. East Mediterr Health J 2011;17(1):749.

19. Rehman A, Rehman T, Shaikh MA, Yasmeen H, Asif A,Kafil H. Pakistani medical students' specialty preference and the influencing factors., 2011;61(7):713-8,

20. Asif M, Bukhari SMR, Ahmad A. Research Trend, Career Preferences and its Effective Factors among Undergraduate Medical Students in Jinnah Sind Medical University, Pakistan.Future Med Educ J 2015;5(3):3-7.

21. Lambert EM, Holmboe ES. The relationship between specialty choice and gender of U.S. Medical students, 1990-2003. Acad Med 2005; 80(9):797-802.

22. Khader Y, Al-Zoubi D, Amarin Z, Alkafagei A, Khasawneh $\mathrm{M}$, Burgan S, et al. Factors affecting medical students in formulating their specialty preferences in Jordan. BMC Med Educ2008;8(1):32.

23. Hajizadeh S, Mahmoodian H.Factors affecting the choice of specialty in medical students in Iran. Journal Of Medical Education 2018;17(2):100-8. 